\title{
PRODUÇÃO CULTURAL E COMPARTILHAMENTO DE SABERES EM REDE: ENTRAVES E POSSIBILIDADES PARA A CULTURA E A EDUCAÇ̃̃O
}

\author{
Nelson De Luca Pretto* \\ Salete Noro Cordeiro** \\ Washington dos Santos Oliveira***
}

RESUMO: Neste artigo, analisa-se, por um lado, a emergência e o crescimento de espaços de produção social em rede e, por outro, como esses espaços, potencialmente ricos para compartilhamento e usufruto de bens e recursos, encontram-se continuamente ameaçados por uma concepção privatista e proprietária de produção e circulação culturais. $\mathrm{Na}$ senda da ética de colaboração dos hackers, da filosofia do software livre e de código aberto, do acesso livre e das licenças abertas, apresentam-se perspectivas outras de atividades contra-hegemônicas de produção e compartilhamento de conteúdos e conhecimentos. Analisam-se as ações das corporações no interior das escolas, visando a incorporar práticas centradas no não compartilhamento de informações. Por fim, conclui-se o artigo com uma análise sobre as potencialidades desses processos para a produção e circulação de cultura, bem como para a educação.

Palavras-chave: Propriedade Intelectual; Direito Autoral; Ética Hacker, Compartilhamento em Rede; Educação.

* Doutor em Comunicação pela Universidade de São Paulo (USP); Professor Associado da Faculdade de Educação da Universidade Federal da Bahia (UFBA). E-mail: nelson@pretto.info.

* * Doutoranda em Educação pela Universidade Federal da Bahia (UFBA); Professora Assistente da Faculdade de Educação da Universidade Federal da Bahia (UFBA). E-mail: salete.norocordeior579@gmail.com.

** Mestrando em Filosofia pela Universidade Federal de Sergipe (UFS); Professor do ensino médio. E-mail: washing32@hotmail.com. 


\section{CULTURAL PRODUCTION AND KNOWLEDGE SHARING NETWORK:} BARRIERS AND OPPORTUNITIES FOR CULTURE AND EDUCATION

ABSTRACT: This paper analyses the emergence and growth of digitally networked spaces of social production and examines how such spaces, which are potentially rich for sharing and enjoyment of goods and resources, are continuously threatened by privatization and the proprietary logic of cultural production and circulation. In the wake of the hacker ethic of collaboration, the philosophy of Free and Open Source Software, Open Access and Open Licenses, the paper presents perspectives of other counter-hegemonic activities of producing and sharing content and knowledge. We conclude the paper by analysing the potential of these processes for cultural production and circulation and for education.

Keywords: Intellectual Property; Copyright; Hacker Ethic; Sharing Network; Eeducation.

\section{Introdução}

A proposta do artigo é colocar em tensão alguns pontos que vêm ganhando destaque na academia e na mídia, relacionados à produção científica e cultural ${ }^{1}$ e ao seu compartilhamento a partir das tecnologias digitais em redes. Parte-se de uma contextualização histórica, dialogando com algumas reflexões sobre os modos de construção das legitimações de práticas que procuram cercear ${ }^{2}$ a produção cultural descentralizada através da exigência normatizante e excludente da propriedade intelectual. A partir disso, discute-se o modo como essas práticas acabam por desfavorecer a apropriação coletiva dos saberes construídos historicamente.

No interior dessa discussão, situam-se os conflitos de interesse entre as esferas públicas nacionais e as dimensões privadas das corporações globais em relação à apropriação dos meios e processos de produção dos conteúdos científicos e culturais, caracterizando alguns jogos de poder que envolvem as dimensões sociais do conhecimento e da produção de cultura. Nesse jogo, abordado a seguir, quase sempre as grandes corporações têm uma grande influência - poder de barganha sobre as decisões - fazendo com que a soberania dos Estados-Nação seja cada vez mais enfraquecida nos processos políticos de gerência dos fluxos e produção de bens culturais, com reflexos diretos para os sistemas educacionais. 
Instaura-se, dessa forma, uma verdadeira ditadura das corporações transnacionais através das Políticas de Propriedade Intelectual (PI), pelas quais o conhecimento torna-se mercadoria com alto valor, sendo suplantados os direitos sociais de acesso livre e aberto ao conhecimento. Entendendo que o cerceamento do conhecimento como propriedade particular de poucos é incompatível com o desenvolvimento da ciência, da cultura e da educação, verificar-se-á que os movimentos contrahegemônicos, especialmente os ligados aos softwares livres, acessos livres e licenças abertas, têm criado várias alternativas, nas últimas décadas, por meio das diversas ações entre pares na rede, ressignificando os usos e as normas de distribuição e acesso dos bens resultantes da produção cultural coletiva, com significativa contribuição para a implantação de processos abertos de produção cultural e científica na educação.

\section{Breve percurso histórico do conceito de propriedade intelectual}

A propriedade intelectual, enquanto "relações de propriedade sobre criações do intelecto" (SALUM, 2009, p.20), é uma modalidade de propriedade tipicamente moderna, cujos antecedentes históricos possibilitam uma melhor compreensão dos atuais entraves jurídicos e ideológicos que envolvem os processos de produção e compartilhamento de conteúdos (agora digitais). Nesse sentido, importante observar como a propriedade intelectual foi-se desenvolvendo no interior de um modelo econômico pautado nos pressupostos da propriedade material territorializada, como sugerem Imre Simon e Miguel Said Vieira (2008), Gabriel Cunha Salum (2009), Fabrício Solagna e Bruno Bunilha Moraes (2010), entre outros.

Gabriel Salum (2009, p.32) parte da dimensão legal da propriedade privada no seio da Roma Antiga para discutir a "eficiência do direito romano como elemento regulador das relações sociais em geral e das relações de propriedade em particular". Segundo o autor (2009, p.33), a propriedade privada, na Roma Antiga, sustentava-se em uma concepção do direito que poderia ser traduzida por três características básicas: direito absoluto ("na medida em que era oponível contra todos os membros da sociedade"), direito exclusivo ("pelo fato de poder existir apenas uma única propriedade em um mesmo solo") e direito perpétuo 
("pelo fato de ser insuscetível de ser adquirida por um dado período a título provisório ou condicionalmente").

Essa concepção de direito, no que se refere à propriedade no mundo romano, está com raízes bem fincadas no solo, não sendo isso apenas uma metáfora, porque a propriedade, estando assentada na terra, constituía-se, expandia-se e transmitia-se em função da territorialização dos bens, fossem eles ferramentas, mercadorias ou força de trabalho, entre outros. Essa concepção de enraizamento da propriedade na materialidade territorial vai-se desenvolvendo nos períodos históricos subsequentes, até mesmo quando não mais se justificaria por si própria. Com a queda do Império Romano do Ocidente, grande parte da Idade Média europeia passa a reestruturar as bases dos seus modos de produção e de suas relações de poder em função do modelo de propriedade que passa então a vigorar. Ainda de acordo com Gabriel Salum (2009, p.34), “a desagregação da organização social escravista característica do mundo antigo e a ascensão da ordem feudal" foram as marcas desse momento histórico e, com isso, a definição das extensões e dos limites na Idade Média, bem como os princípios conceitualizadores de propriedade e proprietário, passam a ser delimitados no interior de um sistema baseado na propriedade relativamente coletiva e compartilhada da terra sob domínio da figura do senhor feudal e de sua legitimação pela Igreja Católica. Nesse contexto, a posse e a propriedade davam-se por meio de relações de vassalagem que estruturavam o modo como eram distribuídos, ocupados e usufruídos os meios materiais da produção econômica da época medieval. Nas palavras de Imre Simon e Miguel Said Vieira (2008, p.16), o uso das terras, não obstante envolvesse relações de exploração, "estava sujeito a regras ligadas à equidade, à transparência e a garantia da sustentabilidade".

A partir da época que coincide com o declínio da Idade Média, surge, na Inglaterra, um movimento denominado enclosure, que nada mais foi do que o "cercamento" desse espaço coletivo, ou seja, a privatização do espaço que antes era usado coletivamente. Esse movimento surgiu como reflexo do que se operava em termos políticos, sociais e econômicos na inauguração da modernidade. Como afirma Gabriel Salum (2009, p.39), "o novo modelo de propriedade adotado pelas sociedades europeias da modernidade era nada mais nada menos que o resgate e a readequação para um novo contexto histórico daquela 
mesma noção individualista de propriedade utilizada pelo Império Romano [...]".

Juntamente com a reformulação moderna do direito clássico da propriedade privada sobre os bens materiais, uma nova regulamentação foi sendo elaborada com o intuito de resguardar os direitos sobre um tipo diferente de propriedade, surgindo o conceito de Propriedade Intelectual (PI), desconsiderado pelos romanos e pelos povos anteriores à modernidade europeia.

O movimento de cercamento dos espaços e de enfraquecimento dos commons se deu na conjuntura da expansão da colonização mercantilista das terras recém-descobertas nas Américas. Enquanto isso, a privatização dos espaços ocupados pelo Velho Mundo deu condições para o levantamento de muros cada vez mais altos, sejam eles os dos mosteiros clericais, dos castelos aristocráticos ou ainda os dos burgos que já despontavam, ampliando seu tamanho. Era dentro desses muros que se gestava a burocratização urbana dos fluxos de bens materiais (mercadorias) e simbólicos (informação e conhecimento) como são conhecidos hoje.

No que diz respeito aos fluxos de bens simbólicos, essa conjuntura coincide com o desenvolvimento da indústria tipográfica (século XV), que passa a controlar o acesso aos conteúdos intelectuais através dos meios materiais que veiculam esses conteúdos, agora impressos e não mais copiados pelas mãos dos copistas. A prescindência dos mosteiros e de seus copistas para a multiplicação e conservação dos conhecimentos acumulados historicamente não só deslocou o espaço de configuração dos rumos ideológicos que tomariam a sociedade, como também se tornou um forte condicionante do modelo econômico e jurídico, que se foi construindo nas primeiras cidades modernas. Esse fato beneficiou a emancipação sociopolítica burguesa, que não se deu sem resistência da aristocracia da época. De acordo com Lucia Mury Scalco:

Com a invenção da imprensa, os soberanos sentiam-se ameaçados com a iminente democratização da informação e criaram um ardiloso instrumento de censura, consciente em conceder aos donos dos meios de produção dos livros o monopólio da comercialização dos títulos que editassem, a fim de que estes, em contrapartida, velassem para que o conteúdo não fosse desfavorável à ordem vigente (SCALCO, 2010, p.161). 
Os burgueses diretamente ligados à imprensa, como intermediários entre os "criadores" e os "consumidores" das obras literárias e científicas, vão, no bojo dos conflitos de interesses entre clero e aristocracia, definir como a sociedade ocidental deve gerir o fluxo de informações e conhecimentos. Com isso, vai-se delineando o lugar do proprietário dos meios de circulação dessas informações e conhecimentos, e dos bens materiais mercadologizados que, uma vez manufaturados, passam a agregar em si mesmos esses conhecimentos.

Com o pretexto de proteger os direitos de autoria do criador da obra e incentivá-lo a criar mais, essas iniciativas definiram os modos de produção, circulação e fruição dos bens culturais, demarcando as fronteiras do território legal de fluxo do conhecimento, bem como das estratégias de mercado para apropriação dos bens culturais por parte de entidades individualizadas. Ao mesmo tempo, um novo modelo de sociedade estruturar-se-ia junto aos recém-formados Estados-Nação modernos, modelo esse calcado na defesa do direito individual à propriedade como garantia à liberdade e na apologia romântica ao estímulo e recompensa ao gênio criador, bem como na ética privatista e exclusivista do protestantismo (HIMANEN, 2001; SOLAGNA; MORAES, 2010).

Trata-se de "regimes" que vêm sendo construídos a partir da introdução de significados artificiais para valorizar certas práticas privatistas em detrimento de uma apropriação coletiva dos bens sociais. Evidencia-se esse processo a partir do uso da retórica da propriedade intelectual como racionalidade econômica e, com isso, tenta-se convencer de que os bens intelectuais têm origem na esfera privada (de meios de produção materiais), cuja regulação deve continuar a ser feita por regras antes aplicadas à propriedade da terra e dos bens materiais, sendo, nessa concepção, a forma mais acertada de gerir esses recursos. "O vocabulário e os conceitos que temos à nossa disposição para pensar a produção imaterial foram sendo construídos sob essa perspectiva: a valorização do aspecto privado da produção intelectual, e, consequentemente, da propriedade privada dessa produção" (SIMON; VIEIRA, 2008, p.26).

Essa é a herança legada aos tempos contemporâneos com trágicas consequências para a ciência e a educação, como será visto adiante. Atualmente, as normatizações que tratam sobre produção e difusão da cultura se estruturam ainda ancoradas em concepções de direito cap- 
ciosamente criadas na sociedade capitalista do início da era moderna, calcadas na antiga noção de propriedade material. Esses pressupostos, pensados desse ponto de vista, procuram legitimar os interesses dos detentores dos meios de produção através de práticas que vão de encontro aos direitos coletivos de acesso ao conhecimento e aos resultados dos processos culturais.

\section{Propriedade intelectual como trunfo das corporações}

A apropriação da produção, circulação e consumo dos conteúdos culturais, nos dias de hoje, se dá de forma majoritária, privativamente, pelas corporações transnacionais, em uma sociedade em que o conhecimento e as produções intelectualmente elaboradas tornaram-se a principal estrutura do capital globalizado.

Embora global e cada vez mais virtualizada, a propriedade intelectual dos bens culturais está submetida às ações concentradas em lugares estratégicos, onde são tomadas as decisões políticas que definem as fronteiras dentro das quais os conteúdos culturais fluem e são acessados. Locais esses que, cada vez mais, ampliam-se de forma bastante agressiva, já que essas corporações globalizadas vão-se tornando mais fortes que os próprios governos locais, justamente por conta do controle sobre a produção e distribuição de cultura. São exemplos dessas corporações as grandes casas editoriais de livros - inclusive didáticos e científicos - e de revistas acadêmicas, a indústria do entretenimento, as empresas produtoras de software e hardware de computadores, entre outros.

Desde os trabalhos de Hobbes (1997) e Locke (2005), cada vez mais, ficava explícito que a proteção da propriedade privada, em toda a sua dimensão, constituía-se, paradoxalmente, em uma das principais funções sociais a que se destinava o Estado. Através de mecanismos legais, cuja legitimação e intensificação são advindas do liberalismo moderno, a propriedade intelectual (definida como monopólio de exploração dos bens intangíveis pelo sujeito criador) desenvolveu-se artificialmente na senda do mesmo modelo econômico da propriedade material - com base na territorialidade dos bens, inserida no contexto do modelo do cercamento inglês (enclosure), já mencionado. 
Atualmente, não obstante os suportes técnicos e os modos de apropriação das tecnologias estarem passando por profundas transformações com a digitalização dos processos, percebe-se que as políticas globais de acesso aos meios e conteúdos resultantes da criatividade coletiva têm, anacronicamente, procurado intensificar não só a restrição e o controle, mas a verdadeira usurpação dos conteúdos (commons). Para Henrique Parra (2011, p.16), baseado em Moulier-Mountang, isso se dá em função da conversão do bem coletivo em capital imaterial, constituindo-se em uma "versão atualizada dos enclosures ingleses da fase de acumulação primitiva do capitalismo". Ainda, segundo o autor:

Se, nos séculos XVII e XVIII, os enclosures foram fundamentais para a expropriação da propriedade comunal das terras e instauração de um novo conceito de propriedade privada, atualmente, vemos uma disputa análoga sobre o commons (conhecimentos, saberes, cultura, etc.), inaugurada pelas mídias digitais (PARRA, 2011, p.16).

Como ainda será detalhado, a justificativa jurídica para essa legitimação da restrição dos commons é inadequada, como o é o argumento de que o direito de propriedade intelectual de uma obra é a garantia de proteção dos interesses do sujeito criador sobre sua criação, quando, em última instância, o que se evidencia, tanto no mercado editorial como científico - em última instância, os mesmos! - é que são os lucros das corporações ${ }^{3}$ que intermedeiam o acesso às obras.

Mais poderoso do que o Leviatã de Hobbes, a corporação ganhou privilegiado lugar na cena mundial e impôs aos Estados mais fragilizados não só modelos econômicos como também critérios para avaliar a eficiência com que são administrados seus próprios interesses. Mais do que isso, usa o poder de estabelecer bloqueios, embargos e boicotes aos países que desrespeitam os tratados como mais uma das poderosas formas de controle. Segundo Othon Jambeiro (1995, p.167), "tais corporações são agora suficientemente grandes para competir com os governos, e tão desejadas como parceiras em projetos econômicos que podem ser motivos de fortes disputas entre governos nacionais."

No campo da propriedade intelectual, as corporações, com o apoio dos governos norte- americanos, japoneses e da União Europeia, têm desenvolvido estratégias reguladoras através de diversos fóruns internacionais, impondo leis que afetam a soberania de vários países, 
restringindo o acesso ao conhecimento, à cultura e à ciência. Segundo Ondina Leal e Rebeca Souza (2010), desde o pós-Segunda Guerra Mundial, inicia-se um reordenamento econômico que acontece de forma global, com o objetivo de intensificar a regulamentação dos novos mercados, com o surgimento do Banco Mundial (BM) e do Fundo Monetário Internacional (FMI).

$\mathrm{Na}$ década de 80, do século passado, intensifica-se o debate sobre PI, tendo sido criado, em 1984, o acordo internacional TRIP (Acordo Relativo aos Aspectos do Direito da Propriedade Intelectual, em inglês: Agreement on Trade-Related Aspects of Intellectual Property Rights) no âmbito da Organização Mundial do Comércio (OMC). Esse acordo intensificou o controle referente às "formas de propriedade sobre bens intangíveis, tais como conhecimento, símbolos, procedimentos, modos de vida, ideias, conhecimento tradicional, enfim, cultura" (LEAL; SOUZA, 2010, p.14), impondo várias restrições e sanções aos países signatários, entre elas, a imposição de garantir o mais elevado nível de proteção em relação à PI, impedindo os países de criarem sua própria regulação interna, conforme suas necessidades. Interessante observar que o tratado em questão não está vinculado à Organização Mundial de Propriedade Intelectual (OMPI) e sim à Organização OMC, e isso se dá porque um país, ao aderir à OMPI, não fica obrigado a aderir a todos os tratados administrados por essa organização, enquanto que, ao inserirem a TRIP na OMC, a adesão passa a ser obrigatória e na sua totalidade, de forma que, para integrar os mercados de livre comércio, que é o objetivo da OMC, um país deve não apenas prever regulamentar localmente o acordo, como garantir sua eficácia (TARGA; DEITOS; SOUZA, 2010). Com isso, países e iniciativas que não estiverem de acordo com os tratados sobre propriedade intelectual correm o risco de sofrer interferências judiciais, comprometendo suas soberanias.

A privatização dos saberes e práticas das produções artísticas, científicas ou tecnológicas, definida pelas grandes corporações mundiais, determina os modos como os governos nacionais passam a gerir suas políticas normativas relacionadas à produção e circulação de cultura, incluindo-se aí, obviamente, ciência e tecnologia, e, com isso, ocasionando graves consequências para o uso na educação, em todos os níveis.

O site sueco de compartilhamento de arquivos em torrent, ${ }^{5}$ The Pirate Bay, serviu como bode expiatório de ações para combater as prá- 
ticas de compartilhamento, mostrando, mais uma vez, a força dessas corporações. Para entender melhor o caso, é importante salientar que, antes do ataque ao The Pirate Bay, a Suécia não havia definido leis que criminalizassem as práticas de compartilhamento de conteúdos culturais pela internet. Com a intervenção explícita norte-americana, aconteceu o ataque a esse site: houve fortes perseguições por parte das gigantes indústrias do entretenimento, como a Columbia Pictures, Sony e Warner Bros, que mobilizaram as cortes internacionais, por meio do governo norte-americano, para impetrar ações contra ele. $\mathrm{O}$ argumento utilizado era o de que o site facilitava o download de arquivos (músicas, filmes, etc.) e, com isso, violava, de forma objetiva, as leis sobre PI. A pressão internacional foi enorme e, por fim, em abril de 2009, os fundadores do site foram condenados pela corte sueca à sentença de um ano de prisão e pagamento de indenização no valor de 3,3 milhões de euros.

Esse é apenas um exemplo, entre tantos outros, da atuação repressiva das corporações para a manutenção dos seus interesses privados. Mas, além da atuação repressiva, elas também atuam através do que denominam de "formação" dos sujeitos consumidores, penetrando direta e explicitamente nos sistemas educacionais e nas escolas.

A Câmara de Comércio Americano (AmCham: American Chamber of Commerce $)^{6}$ é um exemplo dessa segunda linha, explicitando como as corporações (associadas aos interesses dos grandes grupos midiáticos) criam estratégias de enfrentamento e manutenção do poder frente ao dinamismo das redes (de compartilhamento e colaboração) por essa via da "conscientização" dos jovens frente à chamada "pirataria", qualificando como ilegais as iniciativas de compartilhamento.

Ligada a um conjunto de grandes conglomerados corporativos, dentre eles, Medley, Merck Sharp \& Dohme, Shering-Plough, Microsoft e MPAA (Motion Picture Association of America), este último representando os principais estúdios de cinema, entre outros - todos fazendo parte da OMC - a AmCham tem desenvolvido projetos nas escolas da América Latina, incluindo o Brasil, oferecendo às redes públicas e privadas de ensino cursos de "formação" contra a "pirataria", através do "Projeto Escola Legal: combater a pirataria se aprende na escola". Criado em 2006, com a intenção de atacar a prática do compartilhamento a partir de uma iniciativa educativa, o projeto estrutura-se tendo 
como base uma cartilha, intitulada $A B C$ do PEL, de cursos de "sensibilização" para professores e de um encontro anual (Fórum de Educadores no Combate à Pirataria), no qual os professores recebem materiais e formação para se tornarem multiplicadores do projeto. São realizadas palestras, oficinas, visitas nas escolas, formação dos professores, atividades coletivas com apresentação de alunos e professores dos trabalhos produzidos durante o período letivo (cartazes, desenhos em quadrinhos, teatro, coreografias, músicas), sempre com foco no conceito de "pirataria". Obviamente, esse material não apresenta uma discussão ampla sobre o tema, oferecendo somente uma única visão em relação à PI, sem mencionar, em nenhum momento, outras alternativas que são criadas a partir das tecnologias digitais, no que tange a outras formas de apropriação, como as exceções já previstas na legislação de Direitos Autorais, no crescente uso de Recursos Educacionais Abertos (REA) em todo o mundo, da discussão sobre o commons e sobre a democratização do acesso aos bens culturais. O texto da cartilha traz uma argumentação baseada na legalidade, justificando que as leis "são regras sociais que determinam os deveres e garantem os direitos da cidadania, protegendo os cidadãos e possibilitando a vida em sociedade" (AUTOR???, ano???, p.9).

Tanto a ação repressiva, como a chamada "educativa" das corporações são, no entanto, fortemente combatidas por uma intensa e ativista articulação da sociedade civil organizada que passa a usar intensamente a própria internet para combater esses movimentos. Configuram-se, assim, alternativas contra-hegemônicas em relação às práticas das grandes corporações, tanto no ciberespaço como fora dele, desconfigurando territórios e propondo a eliminação das fronteiras, tanto físicas como normativas, por meio de uma ética de colaboração e de compartilhamento através de iniciativas ativistas e libertárias nas teias da internet. 


\section{A internet, seus embates e as possibilidades de produção colaborativa de cultura}

A internet teve sua origem pelas mãos dos cientistas militares nos Estados Unidos, no final da década de 60 do século passado, por meio da Arpanet (Advanced Research Projects Agency Network). Isso se deu no período da guerra fria, em um momento em que a paisagem político-econômica dividia-se em dois grandes blocos, liderados, por um lado, pela União das Repúblicas Socialistas Soviética e, por outro, pelos Estados Unidos da América, história essa bastante conhecida. ${ }^{8}$

O importante, para o contexto deste artigo, é que, fundamentalmente, a internet se constitui, a partir daqueles primeiros momentos, como um grande exemplo de política pública e de ação ativista, preocupada, essencialmente, com a descentralização de servidores e dados baseados em princípios colaborativos, que passaram a constituir aquilo que ficou conhecido como sendo a "ética dos hackers", em uma alusão ao livro de mesmo nome do filósofo finlandês Pekka Himanen (2001).

Para Steven Levy, autor do livro Os heróis da revolução (2012), o que os hackers fizeram foi criar uma filosofia "que parece estar atrelada ao elegante fluxo lógico da computação. É uma filosofia de compartilhamento, abertura, descentralização e do prazer de colocar as mãos sobre as máquinas a qualquer custo - desde que seja para aprimorá-las e também ao mundo" (LEVY, 2012, p.VII).

Para os hackers, no contexto do nascimento da internet, a rede não poderia ser propriedade de grupos, sejam eles militares, cientistas ou as grandes corporações que já começavam a perceber as potencialidades das tecnologias digitais de informação e comunicação. Além de uma forte atuação em programação, esses novos personagens da contracultura passavam a atuar de forma ativista, seja invadindo sites e criando mecanismos para burlar sistemas de comunicação, ou simplesmente desenvolvendo peças (hardware) e linguagens (softwares) para que as máquinas pudessem processar informação e se comunicar. Para eles, esses saberes, resultado do acúmulo do desenvolvimento cultural de gerações, deveriam ser abertos para que os sujeitos deles se apropriassem livremente. Isso porque, para muitos daqueles coletivos, a produção em rede, mediada pelas tecnologias, possibilitaria uma reordenação da produção da ciência e da cultura, de sua divulgação e da criação de novas 
atitudes frente às próprias tecnologias. Como já mencionado, era preciso aprimorar as máquinas e "também o mundo" (LEVY, 2012, p.VII).

Aqui convém um parêntese para que se possa compreender o funcionamento da internet e um dos seus aspectos que é dos mais fundamentais em termos conceituais. Ao, prioritariamente, usar, entre outros, o protocolo TCP/IP (Transfer Control Protocol/Internet Protocol), o que se buscou, no desenvolvimento da internet, foi conectar máquinas diferentes, presentes também em diferentes redes, não se preocupando em adaptar nem a máquina nem a rede para que elas pudessem "conversar" entre si. Buscou-se, assim e prioritariamente, facilitar a interconexão entre todos os sistemas, e, seguramente, foi o que terminou fazendo a internet ser conhecida como uma metarrede e expandir-se brutalmente pelo mundo. Assim, "a internet surge possibilitando uma plataforma de comunicação distribuída, prenunciando uma horizontalidade de acesso aos bens de informação na qual múltiplos agentes produzem e distribuem tecnologias" (SOLAGNA; MORAES, 2010, p.96) e, com isso, potencializando espaços abertos de articulação política através da apropriação das mídias e conteúdos digitais por parte de diversos sujeitos. ${ }^{9}$

Mobilizam-se, dessa forma, comunidades até então excluídas dos processos hegemônicos de comunicação de massa, tornando possível uma maior difusão e promoção da cultura e do desenvolvimento científico e tecnológico como um bem comum, em movimento oposto aos processos impostos pelos países hegemônicos e grandes corporações. Dessa forma, pode-se pensar, com a apropriação da infraestrutura tecnológica e das produções emanadas a partir do uso das mesmas, em novas possibilidades para a educação, compreendida aqui em uma perspectiva plural, que busque superar a ideia da transformação do diferente no igual, constituindo-se em uma rede de conexão das diferenças.

As condições necessárias para que isso seja possível vêm-se efetivando fortemente ao longo das duas últimas décadas, sobretudo com o advento da chamada web 2.0, caracterizada pela forte presença dos usuários, denominados “interagentes" por Alex Primo (2008), que passam a atuar de forma mais intensa, cada vez mais protagonistas, na construção dos processos de produção de culturas e conhecimentos. A ampliação dessa apropriação da rede por parte dos cidadãos pode ser 
constatada pela multiplicação de sites, repositórios, blogs, microblogs, comunidades virtuais, entre outros.

Além disso, com a queda dos preços dos computadores e ampliação da presença da computação em outros objetos, como os telefones celulares e tablets, facilita-se a manipulação e reprodução dos bens digitais, gerando uma profusão de textos, imagens e sons na rede, produzidos de forma distribuída. Dessa maneira, qualquer material digitalizado pode ser copiado infinitas vezes, com custo muito baixo ou zero e com qualidade igual ao original. Facilita-se, assim, a distribuição, aumenta-se a eficiência, descentralizam-se os processos, permitindo um amplo uso e remixagem dos conteúdos compartilhados, sem que haja um escasseamento do que é compartilhado.

Obviamente, a criação artificial do escasseamento dos produtos tem interesses específicos para aqueles que querem transformar um bem não rival em um bem rival, ${ }^{10} \mathrm{e}$, com isso, transformá-lo em escasso. A escassez dos bens só se aplica aos recursos rivais que concorrem em seu uso por outra pessoa e não para os produtos e processos digitalizados e que circulam na internet, que podem ser replicados e remixados quase que de forma infinita. Desse modo, a cultura pode ser produzida de maneira descentralizada e circular amplamente sem necessidade de intermediários, atualizando o potencial que a internet tem desde o seu início, especialmente para os processos educativos, formais ou não formais.

\section{Filosofia hacker, software livre e licenças abertas: novas práticas relacionadas à produção e circulação de bens culturais}

As estruturas sociotécnicas contemporâneas criaram condições para o surgimento de uma ética das redes que tem estabelecido novas relações com a cultura. Com as novas práticas mediadas pelas tecnologias digitais, os discursos que procuram defender o controle legal da produção de cultura, por meio da criação artificial de escassez dos bens imateriais, parecem cada vez mais vazios de sentido e, portanto, inaceitáveis. Os processos de produção não se dão mais exclusivamente a partir dos centros emissores de dados para perímetros receptores, e sim a partir de um cenário que favorece a comunicação em que, potencialmen- 
te, cada ponto da rede (descentralizada) funciona ao mesmo tempo como produtor e receptor de cultura. As trocas são intensificadas e outra experiência pode ser vivenciada, constituindo a "ética hacker" (HIMANEN, 2001), ou seja, uma ética movida pela paixão ao compartilhamento.

Ela começa a se configurar nos anos 60 do século passado, movida pelo entusiasmo com relação ao desenvolvimento de programas para computadores, articulando, de forma intensa, a produção de conhecimento com a ludicidade e com o prazer de se desenvolver programas. Invertendo os valores advindos do capitalismo moderno, como diz Himanen, os hackers definem seu tempo de modo livre e compartilham experiências de liberdade, instituindo uma ética pautada por valores como liberdade, criatividade, paixão e colaboração. Esses valores são compartilhados em rede e têm construído espaços/tempos outros em que os conteúdos são abertos para que as pessoas possam livremente se apropriar e construir novos e diversos conhecimentos. A filosofia hacker busca a abertura do conhecimento como fator preponderante, para que, a partir da herança coletiva das criações do espírito humano, haja avanços e aperfeiçoamentos nas técnicas de produção e circulação das informações e do conhecimento, garantindo a ampliação ao seu acesso.

A história da computação e do nascimento do software livre é rica e envolve muita gente. Entretanto, dois desses personagens são emblemáticos: Richard Stallman e Linus Torvalds. O nova-iorquino Stallman, ou simplesmente RMS, vivia o mundo dos computadores desde o ensino médio e, em 1971, passou a trabalhar no tradicional Massachussetes Institute of Technology - MIT (LEVY, 2012, p.409), sempre com a ideia de um "anarquismo construtivo", e já, com isso, prenunciava-se o que passou a ser denominado de ética hacker. Em um computador, conta Steven Levy (2012, p.410), ele deixou uma mensagem que pode ser considerada como uma das bases do que mais à frente seria chamado de ética dos hackers: "[esse anarquismo construtivo] não significa uma selva onde cão-comecão. A sociedade norte-americana já é uma selva onde cão-come-cão, e suas regras mantêm essa situação. Nós, hackers, queremos substituir essas regras em nome da cooperação construtiva".

Stallman, com base nesses princípios, inicia então uma verdadeira cruzada em torno do movimento que ficou conhecido como software livre, cuidando, desde os primeiros momentos, para a garantia de 
que os softwares produzidos dentro dessa filosofia assim continuassem a ser distribuídos. Para tal, criou a Fundação do Software Livre (Free Software Foundantion - FSF) e, simultaneamente, a licença GNU (General Public License), que também ficou conhecida como Copyleft, em um jogo de palavras com Copyrigth.

Para Enid Gabriella Coleman:

Talvez a parte mais engenhosa de sua resposta política foi usar fogo - ou seja, as leis - para lutar contra o fogo. Stallman criou uma licença na qual ele mantinha o direito autoral sobre o seu código, mas permitia a livre distribuição, desde que esta liberdade fosse também estendida para todos os usuários (COLEMAN, 2010, p.133).

Do outro lado do Atlântico, na Finlândia, Linus Torvalds, o criador do kernel ${ }^{11}$ do Linux, foi o outro hacker que, na década de 90, contribuiu para o desenvolvimento das ideias do software livre, já que, ao desenvolver o kernel e o disponibilizar livremente na rede, possibilitou a complementação do que Stallman vinha realizando e, com isso, deu força ao aparecimento do sistema GNU/Linux.

Como esses dois hackers, muitos outros se tornam colaboradores de uma ampla rede, contribuindo para criar, distribuir e aperfeiçoar aplicativos livres a partir de uma ação coletiva e colaborativa. $\mathrm{O}$ que se busca - à medida que se vai criando e disponibilizando um programa que atenda ou que possa vir a atender as necessidades dos usuários/colaboradores - é que estes reconheçam esse esforço, por ser uma necessidade comum, e passem a dar retorno ao programador que disponibilizou o código, ou, simplesmente, o melhorem. Assim, o processo de se detectar falhas e produzir soluções é sempre aberto, estabelecendo-se não só a criação de laços sociais, mas a busca coletiva de melhores soluções para o desenvolvimento dos softwares.

Algo bem diferente acontece com os softwares e licenças proprietários dentro da lógica corporativa. Eric Raymond (2008) desenvolveu uma interessante analogia para explicar a forma de trabalho dos hackers na criação de softwares livres, em comparação com o modo proprietário de produção, definindo dois modelos: o bazar, relacionado aos livres, e o catedral, associado aos softwares proprietários.

No modelo catedral, os softwares são criados dentro de um esquema fechado, no qual poucos programadores privilegiados têm sob 
sua responsabilidade o design e o desenvolvimento da arquitetura do sistema operacional e seus aplicativos. Conforme preconiza, em sua página na internet, uma das empresas referência desse modelo, a Microsoft, ${ }^{12}$ esses programadores são os "pioneiros" das culturas e estão preocupados com o "engenho, a criatividade e o progresso" que precisam "seguir, explorando, pensando e criando as próximas grandes invenções". Para tanto, essas empresas defendem que a retenção e o fechamento de um conjunto de conhecimentos em um espaço cercado pelas leis de propriedade intelectual são necessários para continuar oferecendo aos "usuários" um sistema acabado e (per)-feito (no sentido de feito completamente antes de ser disponibilizado), que facilite a vida profissional e pessoal do usuário/consumidor, ao mesmo tempo em que garanta condições para que programadores possam continuar "criando as próximas grandes invenções". ${ }^{13}$ A liberação de um software, nesse modelo, dá-se no momento determinado pela empresa. Porém, ao adquirir o software, o consumidor não o adquire de fato, mas, tão somente, passa a ter a licença para utilizá-lo, e, mesmo assim, com inúmeras restrições, não sendo possível compartilhar o conteúdo do software entre seus pares. No modelo catedral, o compartilhamento de cópias entre os pares é sempre entendido como um atentado - que eles denominam inadequadamente de "pirataria" - contra a Propriedade Intelectual. Como esse é um movimento que cria uma escassez artificial, as grandes corporações do software proprietário - e de toda a indústria cultural tradicional - concentram seus esforços no combate à circulação desses bens, através de pressões exercidas nos governos nacionais para a instituição de uma legislação dura de combate a essa prática disseminada intensamente em função da digitalização dos processos e da internet.

Já o modelo bazar, representado em especial pela filosofia do GNU/Linux e sua licença aberta GPL, funciona com uma dinâmica radicalmente inversa ao modelo catedral, uma vez que o que existe é um estímulo para que as cópias sejam compartilhadas entre os pares. As palavras de ordem dos programadores em relação aos softwares por eles desenvolvidos são libere cedo e frequentemente. Com isso, permite-se que cada interagente na rede participe no desenvolvimento coletivo e aberto do conhecimento e crie continuamente novas soluções para os softwares. Liberar o código cedo e frequentemente significa enviá-lo mesmo com falhas e com erros. Essas lacunas deixadas pelos códigos são fonte 
de interesse dos usuários interagentes e desenvolvedores distribuídos na rede. Identificar erros não significa apenas resolvê-los, mas criar outras soluções para cada projeto, uma vez que, na lógica hacker, a intenção não é poupar os usuários dos erros, e sim compartilhar com eles todas as fases de construção, abrindo possibilidades para que todos possam livremente usar para qualquer fim (princípio 0), estudar o código (princípio 1), compartilhar e ou modificar cópias (princípio 2) e distribuir as cópias, modificadas ou não (princípio 3), através do pleno acesso ao código. Esses princípios foram, pouco a pouco, sendo apropriados por usuários/desenvolvedores, criando-se uma teia global, descentralizada e colaborativa, constituindo-se naquilo que hoje se conhece como o Movimento Software Livre.

E. Gabriella Coleman (2010) usa a expressão "cimento cultural" para definir o significado que tem a liberdade de produção e de compartilhamento de conteúdos culturais e conhecimento na rede, mostrando o quanto é indispensável, para programadores, artistas, cientistas, educadores, entre outros, a garantia de abertura cultural do ciberespaço. É só com essa abertura e liberdade que as trocas podem fluir, de modo que não só cada parte, mas o todo social saiam ganhando nas trocas. $\mathrm{E}$ quanto mais isso acontece, como em um círculo virtuoso, mais abertura e liberdade estimulam a produção de novos elementos culturais a partir dos já existentes. Instala-se o que vem sendo denominado de cultura remix, um tipo de cultura que se desenvolveu no interior das práticas da internet, em que é permitida e incentivada a criação de obras derivadas, em uma combinação ou edição de materiais já existentes.

Lawrence Lessing (2008), mais ou menos na esteira de Eric Raimond, com o seu catedral e bazar, apresenta duas metáforas que funcionam bem para definir a cultura do remix em contraposição à cultura proprietária. Esta última, ele chama de Read Only Culture (analogia a um CD que, por ser "fechado", possibilita apenas a sua leitura). Aqui, a produção da cultura fica a cargo de um pequeno grupo, e a grande massa tem acesso somente como consumidora dessa produção (na imagem do $\mathrm{CD}$, apenas com a visualização e leitura da produção). Essa cultura é defendida com o argumento de que favorece a proteção dos autores e promove o incentivo à produção. O segundo conceito é Read/Write Culture (agora com a analogia a um CD-RW, que, além de ser lido, pode ser gravado), ou seja, indicando que qualquer sujeito pode alterar o con- 
teúdo do disco, acrescentando ou removendo partes. Dessa forma, nessa cultura, cada um estaria contribuindo para produzir novos materiais, já que os sujeitos não são meros consumidores, mas, sobretudo, produtores ativos de cultura, que, dessa forma, será mais rica e diversa.

Entende-se que não existe uma única obra humana que não seja de algum modo derivada direta ou indiretamente de outra obra, e, por isso mesmo, considera-se injustificável que, no atual contexto histórico do copia-cola-remixa-distribui, as leis de propriedade intelectual que protegem os direitos de exploração das corporações sobre essas obras imponham restrições privatistas do usufruto dos bens científicos e culturais, impedindo que os diferentes sujeitos se apropriem desses bens, ressignificando-os e, com isso, ampliando seu usufruto social.

De softwares e licenças proprietários aos softwares e licenças livres e abertos muitos passos foram necessários. Esse percurso tem demonstrado a importância de se pensar em uma concepção de conhecimento e cultura não mais aprisionada no interior de modelos monopolistas, mas como livres jogos lincados a valores e práticas que compreendam essas esferas como públicas, a serem coletivamente apropriadas e configuradas em novas formas de cultura. Se, hoje, a internet cria um mar de possibilidades a serem navegadas, isso reflete uma cultura de liberdade que entende que o conhecimento deva ser aberto, por se constituir em um bem de todos, em oposição àqueles que defendem um legalismo privatizador das grandes corporações, que se beneficiam, privadamente, desse conhecimento, para exercer seu poder político e econômico sobre os indivíduos.

\section{Considerações finais}

O discurso instaurado para levar a cabo o projeto de sociedade que defende a propriedade intelectual é contraditório com as condições que são dadas pelas tecnologias digitais em rede, que têm, em suas próprias condições de funcionamento, a arquitetura de compartilhamento. Por isso, os ardis retóricos que são usados para escamotear as tantas desvantagens de uma dimensão fechada do conhecimento, controlada pelos interesses dos intermediadores, não mais estão dando conta do enfrentamento dos movimentos em defesa da liberdade de circulação da pro- 
dução cultural da humanidade e continuam excluindo grande número de pessoas do acesso aos bens criados coletivamente.

Um olhar mais profundo para as práticas que vêm sendo desenvolvidas nas redes de colaboração e compartilhamento, a exemplo do software livre, pode ser um bom começo para se pensar os bens culturais inseridos em uma dimensão humana de usufruto dos resultados da própria criatividade humana e, com isso, criar alternativas para superar os interesses e modelos de negócios que buscam privilegiar as grandes empresas intermediárias dos bens culturais produzidos pela humanidade. Esses, também, podem-se constituir em importantes princípios para se pensar processos educacionais coerentes com o momento contemporâneo. Processos esses que busquem superar definitivamente a ideia de uma escola que forma apenas consumidores de produtos ou informações. Assim, ao se levar a filosofia hacker para o campo educacional, somam-se, também, as possibilidades trazidas pelo digital para a criação de um ecossistema pedagógico de aprendizagem e produção de culturas e conhecimentos, sempre com esse plural pleno.

A tecnologia digital proporcionou o desenvolvimento de uma cultura vinculada a um alargamento nas concepções de consumo e produção da cultura, logo, esses elementos precisam estar presentes para serem analisados e estudados como balizadores de implementação de políticas públicas de acesso e desenvolvimento da ciência, da cultura e da educação, de forma aberta, bem como de novas estratégias de sobrevivência no mercado, que não sejam as pautadas na exclusão e cerceamento do conhecimento. 


\section{NOTAS}

1 Será feita referência, neste texto, à ciência e à cultura como formas de enfatizar a produção e o conhecimento científico, o que, rigorosamente, seria desnecessário, pois claro está que ciência é cultura, como já bem demonstrou, em sua tese de doutorado, João Zanetic, em Física também é cultura (ZANETIC, 1989).

2 Adiante, com mais detalhes, será explorada a ideia do cerceamento da produção científica e cultural. Uma boa referência sobre o tema é o capítulo "O Rossio não-rival", de Imre Simon e Miguel Said Vieira, no livro Além das redes de colaboração: internet, diversidade cultural e tecnologias de poder, organizado por Nelson De Luca Pretto e Sérgio Amadeu da Silveira, Edufba, 2008.

3 O documentário "A corporação" (disponível em:

<http://www.youtube.com/watch?v=Zx0f_8FKMrY>. Acesso em: 10 ago. 2012.) dos diretores Mark Achbar e Jennifer Abbott (2002), mostra que, embora seja um mecanismo abstrato para consecução dos interesses econômicos de um grupo de pessoas, a corporação foi sendo considerada como um indivíduo de carne e osso do ponto de vista jurídico graças a um precedente judicial de 1886 envolvendo a companhia norte-americana Southern Pacific Railroad e o condado de Santa Clara, Estados Unidos. Favorecendo a companhia, o juiz argumentou que a corporação é um indivíduo que deve gozar de proteção do Estado nos mesmos termos da legislação que defendem os direitos da pessoa humana.

4 Título do livro de Thomas Hobbes que defende a necessidade de um governo central forte para conter o que ele denominou de "um estado de natureza" (caos e guerras civis). Mais informações no verbete na Wikipedia (cf. link: http://pt.wikipedia.org/wiki/Leviat\%C3\%A3_\%28livro\%29).

5 Sistema de transmissão de dados por pacotes distribuídos, que facilitam a obtenção de arquivos com mais velocidade, uma vez que eles estão distribuídos na rede e não baixados de um único lugar central.

6 Disponível em: <http://www.amcham.com.br>. Acesso em: 29 jul. 2012.

7 Disponível em: <http://portaldoprofessor.mec.gov.br/storage/materiais/0000014649.pdf>. Acesso em: 29 jul. 2012 Parcialmente reformulada em 2011 ganha o título de Manual do Educador. Projeto Escola legal. Educação: o melhor caminho para a cidadania. Disponível em: <http://www.projetoescolalegal.org.br/wp-content/uploads/2011/10/MANUAL-DOPEL_completo-set-2011.pdf>. Acesso em 29 jul. 2012.

8 São inúmeros os textos que descrevem e analisam o surgimento da internet. Para mais detalhes, sugerem-se basicamente Levy (2012), Castells (2003) e Pretto (2009).

9 Sempre bom relembrar o histórico movimento dos Chiapas no México, com o subcomandante Marcos à frente, tido como o primeiro guerrilheiro cibernético, em função do intenso uso das redes nas lutas indígenas locais nas montanhas da região de Chiapas. Nesse sentido, sugere-se pesquisar Ceceña (2001).

10 Um bem é rival quando sua utilização por uma pessoa impede o seu uso por outra. Ao contrário, bens e recursos não rivais não competem entre si em seu uso, são bens 
intangíveis, que podem ser usados simultaneamente e compartilhados com outros sujeitos (SIMON; VIEIRA, 2008).

11 Kernel é o núcleo do sistema operacional de um software.

12 Disponível em: <http://www.microsoft.com/brasil/antipirataria/how_intellectual.mspx>. Acesso em: 17 ago. 2012.

13 Disponível em: <http://www.microsoft.com/brasil/antipirataria/how_intellectual.mspx>. Acesso em: 17 ago. 2012.

\section{REFERÊNCIAS}

A CORPORAÇÃO (The Corporation). Direção: Jennifer Abbott e Marck Achbar. Produção: Joel Bakan. Roteiro: Joel Bakan. Intérpretes: Noam Chomsky, Steve Wilson, Jane Akre, Noami Klein, Michael Moore, Vandana Shiva. Canadá: Imagem Filmes, 2003. 1 DVD (144 min).

ABC do PEL. PROJETO ESCOLA LEGAL: Combater a pirataria se aprende na escola. AMCHAM Brasil, 2009. Disponível em:

$<$ http://portaldoprofessor.mec.gov.br/storage/materiais/0000014649.pdf> Acesso em 29 de Jul. 2012.CASTELLS, M. A galáxia da internet. Rio de Janeiro: Jorge Zahar, 2003.

CECEÑA, A. E. Pela bumanidade e contra o neoliberalismo: linhas centrais do discurso zapatista. In: SOANE, J; TADDEI, E. Resistências mundiais: de Seattle a Porto Alegre. Petrópolis/RJ: Vozes, 2001. p.186-199.

COLEMAN, E. G. Revoluções silenciosas: o irônico surgimento do software livre de código aberto e a constituição de uma consciência legal hacker. In: LEAL, O. F.; SOUZA, R. H. V. Do regime de propriedade intelectual: estudos antropológicos. Porto Alegre: Tomo Editorial, 2010. p.131-147.

G1. Fundadores do Pirate Bay são condenados à prisão na Suécia, São Paulo, 01/02/2012. Disponível em:

<http://g1.globo.com/tecnologia/noticia/2012/02/fundadores-do-pirate-bay-saocondenados-prisao-na-suecia.html>. Acesso em: 10 ago. 2012.

HIMANEN, P. A ética dos hackers: o espírito da era da informação. Trad. Fernanda Wolff. Rio de Janeiro: Campus, 2001.

HOBBES, T. Leviatã ou matéria, forma e poder de um Estado eclesiástico e civil. Trad. João Paulo Monteiro e Maria Beatriz Nizza da Silva. São Paulo: Nova Cultural, 1997.

JAMBEIRO, O. A comunicação e o cenário internacional contemporâneo. In: RUBIM, A. A. C. (Org.). Idade midia. Salvador: Edufba, 1995. p.164-184.

LEAL, O.; SOUZA, R. H. V. Do regime de propriedade intelectual: estudos antropológicos. Porto Alegre: Tomo Editorial, 2010.

LEAL, O.; DEITOS, M. A. I; SOUZA, R. H. V. Saúde pública, propriedade intelectual e agenda do desenvolvimento. In: LEAL, O.; SOUZA, R. H. V. Do regime de propriedade intelectual: estudos antropológicos. Porto Alegre: Tomo Editorial, 2010. p.20-29.

LESSING, L. Remix: making art and commerce thrive in the hybrid economy. London, 
Bloomsbury, 2008. Disponível em: http://baixacultura.org/biblioteca/3-livros/remixlawrence-lessig. Acesso em: 10 fev. 2012.

LEVY, S. Os heróis da revolução: como Steve Jobs, Steve Wozniak, Bill Gates, Mark Zuckerberg e outros mudaram para sempre as nossas vidas. Trad. Maria Cristina Sant'Anna São Paulo: Évora, 2012.

LOCKE, J. Segundo tratado sobre o governo: ensaio relativo à verdadeira origem, extensão e objetivo do governo civil. São Paulo: Martin Claret, 2005.

MANUAL DO EDUCADOR. PROJETO ESCOLA LEGAL. Educação: o melhor caminho para a cidadania. AMCHAM Brasil, 2011. Disponível em: <http://www.projetoescolalegal.org.br/wp-content/uploads/2011/10/MANUAL-DO-PEL_completo-set-2011.pdf> Acesso em: 29 jul. 2012.

PARRA, H. Z. M. Sujeito, território e propriedade: tensões estético-políticas sobre a emergência do commons digital, 2011. Disponível em: www.labjor.unicamp.br/MDCC/artigos/art_henrique.pdf. Acesso em: 19 abr. 2011.

PRETTO, N. De L. Uma escola sem/com futuro: educação e multimídia. 7.ed. Campinas: Papirus, 2009

PRETTO, N. D. L; ASSIS, A. Cultura digital e educação: redes já. In: PRETTTO, N. D. L.; SILVEIRA, S. A. da. Além das redes de colaboração: internet, diversidade cultural e tecnologias do poder. Salvador: Edufba, 2008. p.75-83.

PRETTO, N. D. L.; SILVEIRA, S. A. da. Além das redes de colaboração: internet, diversidade cultural e tecnologias do poder. Salvador: Edufba, 2008.

PRIMO, A. Interação mediada por computador: comunicação, cibercultura, cognição. 2ed. Porto Alegre: Sulina, 2008.

RAYMOND, E. S. A catedral e o bazar. 1998. Disponível em: <http://www.dominiopublico.gov.br/download/texto/tl000001.pdf>. Acesso em: 05 maio 2010.

SALUM, G. C. A propriedade intelectual no mundo contemporâneo no contexto geral das relações de propriedade. 118f. 2009. Dissertação (Mestrado em Ciências Sociais) - Faculdade de Ciências e Filosofia, Universidade Estadual Paulista "Júlio de Mesquita Filho", Marília, 2009.

SCLACO, L. M. Camelódromo: a repercussão do regime transacional de propriedade intelectual em nível local. In: LEAL, O. F.; SOUZA, R. H. V. Do regime de propriedade intelectual: estudos antropológicos. Porto Alegre: Tomo Editorial, 2010. p.149-174.

SIMON, I.; VIEIRA, M. S. O Rossio não-rival. In: PRETTO, N. D. L.; SILVEIRA, S. A. Além das redes de colaboração: internet, diversidade cultural e tecnologias do poder. Salvador: Edufba, 2008. p.15-30.

SOLAGNA, F; MORAES, B. B. Patentes de software e propriedade intelectual como estratégia de monopólio. In: LEAL, O.; SOUZA, R. H. V. Do regime de propriedade intelectual: estudos antropológicos. Porto Alegre: Tomo Editorial, 2010. p.95-115.

TARGA, L. V.; DEITOS, M. A.; SOUZA, R. H. V. Duas políticas para a mesma nação: o acesso universal à saúde e o regime de propriedade intelectual. In: LEAL, O. F.; SOUZA, R. H. V. Do regime de propriedade intelectual: estudos antropológicos. Porto Alegre: Tomo Editorial, 2010. p.31-53.

TERRA. Site "Pirata" terá que pagar indenização milionária. Disponível em: <http://tecnologia.terra.com.br/interna/0,, O I 3708856 - E I 4802,00 Site+pirata+tera+que+pagar+indenizacao+milionaria.html>. Acesso em: 08 maio 2011. ZANETIC. J. Física também é cultura. São Paulo: FEUSP, 1989. 
Recebido: 19/03/2013

Aprovado: 05/08/2013

Contato:

Grupo de Pesquisa Educação, Comunicação e Tecnologias (GEC)

Faculdade de Educação

Universidade Federal da Bahia

Avenida Reitor Miguel Calmon, s/n

Vale do Canela

CEP 40110-100

Salvador | BA | Brasil 